\title{
Growth prognosis and growth after menarche in primary hypothyroidism
}

\author{
S Pantsiotou, R Stanhope, M Uruena, M A Preece, D B Grant
}

\begin{abstract}
The long term growth of 20 girls and nine boys with juvenile primary hypothyroidism was studied until they reached final height. At diagnosis the girls had a mean age of 8.8 years (range 3.0-13.0); mean bone age was 5.4 years. The mean age of the boys at diagnosis was 9.5 years (range $3 \cdot 7-14 \cdot 2$ ); mean bone age was 6.3 years. The patients were treated with thyroxine $100 \mu \mathrm{g} / \mathrm{m}^{2} /$ day and serum thyroxine concentrations were maintained in the normal range. During treatment the rate of skeletal maturation exceeded the change in chronological age. Initial mean height SD score for bone age before treatment in the girls was +0.59 and after 11 years of treatment fell to -0.55 . Mean height SD score for bone age in the boys decreased from $+\mathbf{1 . 6}$ to -0.87 during treatment.
\end{abstract}

In the girls the onset of puberty was $1 \cdot 2$ years later than the normal population but the duration of puberty was reduced. Mean age (SD) of menarche was $13.8(1.7)$ years. The pattern of growth in girls with treated hypothyroidism was abnormal as growth continued after menarche, at a time when normal girls have almost stopped growing. During the second year after menarche our patients still had a mean growth velocity of $4 \cdot 1 \mathrm{~cm} /$ year.

Our data suggest that juvenile primary hypothyroidism results in a permanent height deficit. In addition, there is a loss of the normal harmony between growth and sexual maturation in girls, despite adequate treatment, in that growth continues for much longer after menarche than in normal girls.

Acquired juvenile primary hypothyroidism often has an insidious onset characterised by gradual deceleration and eventual cessation of growth. ${ }^{1}$ The initiation of thyroxine treatment in primary hypothyroidism allows rapid 'catch up' growth.

It has been suggested that catch up growth is complete and final height prognosis is realised. ${ }^{2}$ However, there has not been a comprehensive evaluation of growth in children with juvenile hypothyroidism to test this assumption. Analysis of long term growth in congenital hypothyroidism also suggests that catch up is limited when treatment is delayed. ${ }^{3}$ Children treated after the age of 1 year by Bucher et al had accelerated skeletal development and reduced long term growth. ${ }^{3}$ It has been demonstrated that the treatment of prolonged juvenile acquired hypothyroidism results in a permanent height deficit which is related to the duration of thyroxine deficiency before treatment. ${ }^{4}$ It is not known whether the skeletal system responds in an exaggerated manner to normal replacement doses of thyroxine but there are artifacts in the methodology of the estimation of bone age. ${ }^{5}$

There is a normal harmony (or consonance) of the sequence of sexual maturation and its relationship to the spontaneous growth acceleration of puberty. ${ }^{6}$ Usually, peak height velocity in girls during the pubertal growth spurt occurs at breast stage 2 to 3 and menarche occurs concomitant with breast stage 4 when growth velocity has decelerated. ${ }^{7}$ In this retrospective study we have examined growth after menarche in girls with treated primary hypothyroidism after the initial catch up phase of growth had been completed.

\section{Patients and methods}

We have examined the records of patients with juvenile primary hypothyroidism seen over the previous 23 years. Patients were included if they had primary hypothyroidism from prepuberty and no other endocrinopathy or serious illness. All our patients had growth data available from the commencement of treatment to maturity. These criteria were satisfied in 20 girls and nine boys. Unfortunately measured parental heights were unavailable in many of our patients. In the analysis of growth during puberty three girls who had menarche just before diagnosis and subsequently grew a mean of $13.5 \mathrm{~cm}$ are excluded as it was not possible to distinguish between catch up growth due to thyroxine treatment and normal pubertal growth.

In most patients a standard dose regimen of thyroxine $100 \mu \mathrm{g} / \mathrm{m}^{2} /$ day was used. ${ }^{8}$ Serum concentrations of thyroxine and thyroid stimulating hormone were determined every six months during treatment to test short term compliance and point to the necessity for an alteration of thyroxine dose.

Long term growth was analysed by comparison of longitudinal changes in statural growth and skeletal maturation. The growth standards were those of Tanner and Whitehouse. ${ }^{910}$ Bone age was determined by the method of Tanner $e t$ al. ${ }^{11}$ Pubertal development was staged by the method of Tanner. ${ }^{12}$ Testicular size was assessed using a Prader orchidometer. ${ }^{13}$

In normal girls peak height velocity occurs at a mean of 1.4 years before menarche when growth deceleration is maximal. ${ }^{7}$ The correlation of age at peak height velocity and age at menarche is approximately $0 \cdot 9 .^{7} \mathrm{We}$ used these data for the analysis of growth during puberty, 
using the mean growth velocity from the data of Tanner and Whitehouse for normal girls. ${ }^{9} 10$ Differences between mean values were tested by using the $t$ test for unpaired samples.

\section{Results}

Serum concentrations of thyroxine and thyroid stimulating hormone were maintained in the physiological range in all patients and there was no biochemical evidence of overtreatment.

In the girls, mean height SD score for bone. age before treatment was $+0 \cdot 59$. At the age of $17 \cdot 5$ years, after 11 years of treatment, mean height SD score for bone age was -0.55 $(p<0.01$, fig 1$)$. In the boys the mean initial height SD score for bone age was +1.6 and after nine years of treatment at the age of 16.5 years, height SD score for bone age decreased to -0.87 ( $p<0.02$, fig 2). At attainment of adult stature all the patients, except for one girl, were below the 50th centile. 910

In the boys with treated hypothyroidism the onset of genital development occurred at a mean age of $13.3(1.4)$ years, 1.7 years later than normal population. ${ }^{14}$ Their sequence of sexual maturation and its relationship to the growth spurt was indistinguishable from normal boys. By contrast, the pubertal growth spurt in the girls with treated hypothyroidism had different characteristics from those of normal girls. ${ }^{9} 15$ The onset of puberty (breast stage 2) was a mean of 12.4 years, 1.2 years later than normal girls. ${ }^{15}$ Mean age of menarche in our patients was 13.8 years (range 10.9-16.7) compared with 13.5 years in normal girls. Menarche occurred

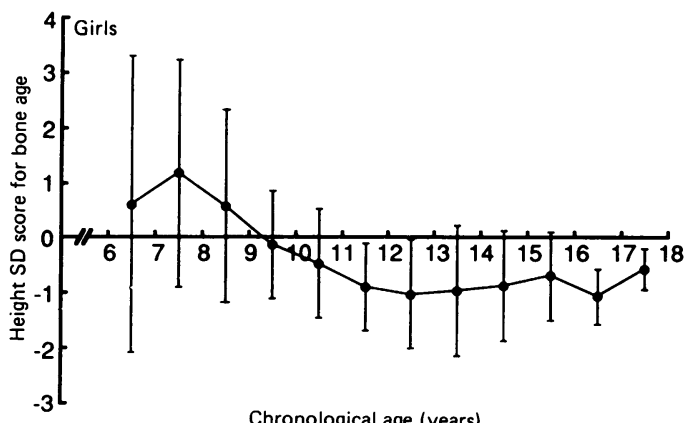

Figure 1 Height SD score for bone age for 20 girls with primary hypothyroidism during thyroxine treatment. Circles represent mean, horizontal bars $1 S D$.

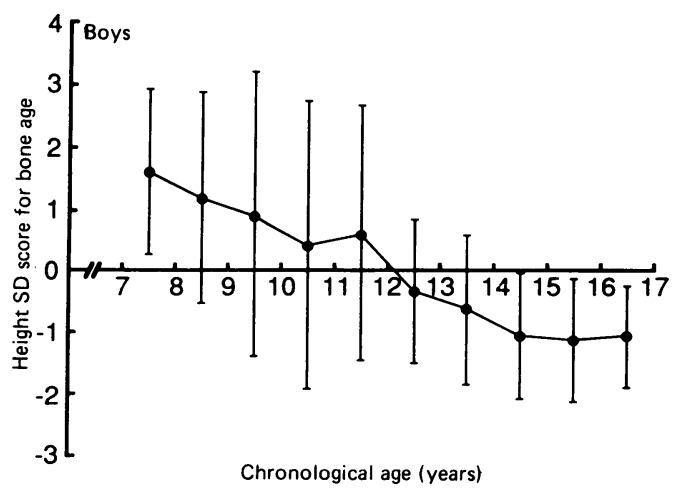

Figure 2 Height SD score for bone age for nine boys with primary hypothyroidism during thyroxine treatment. Circles represent mean, horizontal bars $1 S D$.

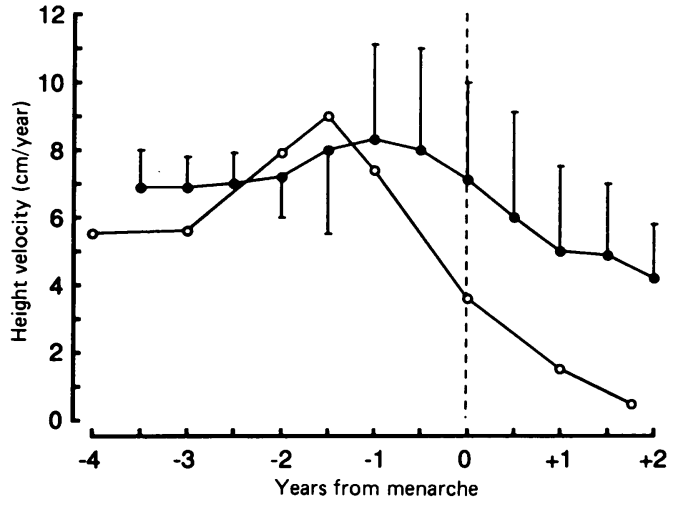

Figure 3 Growth velocity data from 17 girls with primary hypothyroidism treated with thyroxine, related to menarche. Solid circles and horizontal bars represent mean (SD) for patients with hypothyroidism. Open circles represent mean data for normal girls from Tanner et al. ${ }^{10}$ is

at breast stage 4 in our patients, so that the time from the onset of puberty to menarche was reduced in the girls with primary hypothyroidism. Although the intensity of the growth spurt was indistinguishable from normal girls, the pattern of growth differed (fig 3). Growth continued at a faster rate than in normal girls and at menarche mean growth velocity was $7 \cdot 2$ $\mathrm{cm} /$ year. During the first year after menarche, when normal girls have almost stopped growing, our patients had a mean growth velocity of $5 \cdot 1$ $\mathrm{cm} /$ year and during the second year a velocity of $4 \cdot 1 \mathrm{~cm} /$ year (fig 3). However, the girls demonstrated a normal sequence of acquisition of secondary sexual characteristics, which excluded abnormal pubertal development characterised by isolated breast development and raised concentrations of follicle stimulating hormone. ${ }^{16}$

\section{Discussion}

We have demonstrated that catch up growth is incomplete after treatment of long standing juvenile hypothyroidism. Our patients did not attain their genetic growth potential as assessed both by height SD score for bone age. The final height of all the patients, except one, was below the mean for the normal population. Certainly precocious or abnormal sexual maturation were not contributory factors in our patients. ${ }^{16}$ Our findings, in terms of the long term growth sequela of juvenile acquired hypothyroidism, are similar to those of Rivkees et al. ${ }^{4}$

We have based our assessment of height prognosis on height for bone age SD score, predominantly as height at diagnosis in our patients was far below the normal range. Methods of bone age assessment and height prediction vary in their accuracy according to age and diagnosis. ${ }^{17}$ Bone age assessment compares the morphology of the epiphysis and its relationship with the metaphysis. ${ }^{11}$ Certainly hypothyroidism disproportionately affects the epiphysis and it is not surprising that such assessments may deliver low scores. This 'artifact' may explain why bone age scores at diagnosis in primary hypothyroidism are disproportionately delayed to a greater extent than height age. 
Non-compliance may be important because of either over or under treatement. It was impossible to exclude intermittent noncompliance as a contributory factor in our patients. Occasional blood tests, taken at planned clinic visits, assess only short term events and offer no reassurance of longer term compliance. Prolonged severe hypothyroidism may diminish the potential for catch up growth. It may be that delay in the onset of treatment is a critical factor in limiting catch up growth and emphasises the need for early recognition of this disorder. ${ }^{18}$

We do not know what leads to disproportionate catch up in bone age compared with height advance during early treatment. Histomorphometric studies in adults with primary hypothyroidism have shown exaggerated osteoclastic activity and reduced bone mass. This finding may be related to calcium deficiency and is associated with low concentrations of stimulated calcitonin. ${ }^{1920}$ It is probable that multiple factors are involved.

In the girls growth at puberty both in duration and quality was abnormal. Our patients had an abnormal pattern of growth after menarche with loss of the normal relationship between growth and pubertal maturation. The girls continued to grow after menarche even though initial catch up growth had been completed. We can offer no explanation of why girls with juvenile primary hypothyroidism are shorter than expected, despite growing faster and for longer during puberty. The use of a gonadotrophin releasing hormone analogue, to delay the timing and duration of puberty, may be a possible therapeutic approach but results in short normal children have been disappointing. ${ }^{21}$

These observations indicate that the treatment of acquired primary juvenile hypothyroidism is associated with compromised final height despite adequate replacement treatment. In girls after the initial phase of catch up growth associated with thyroxine treatment, both growth and its relationship to pubertal development remain abnormal. Despite the age at onset of primary hypothyroidism, 'adequate' replace- ment treatment with thyroxine does not lead to a normalisation of growth and its relationship to sexual maturation.

1 Talbot NB, Sobel EH, McArthur JW, Crawford JD. Functional endocrinology from birth through adolescence

2 Tanner JM. Catch-up growth in man. Br Med Bull 1981;37 233-8.

3 Bucher H, Prader A, Illig R. Head circumference, height, bone age and weight in 103 children with congenital hypothyroidism before and during thyroid hormone replacement. Helv Paediatr Acta 1985;40:305-16.

4 Rivkees SA, Bode HH, Crawford JD. Long-term growth in juvenile acquired hypothyroidism: the failure to achieve normal adult stature. $N$ Engl f Med 1988;318:599-602.

5 Preece MA, Cox L. Estimation of biological maturity in the older child. In: Bitles A, Collins KJ, eds. Biology of human ageing: symposium proceedings. Cambridge: Cambridge
University Press, 1986:67-80.

6 Stanhope R, Brook CGD. The clinical diagnosis of disorders of puberty: the loss of consonance. Br $\mathcal{F}$ Hosp Med 1986; of puberty:

7 Tanner JM. Growth and endocrinology in the adolescent. In: Gardner L, ed. Endocrine and genetic disease of childhood. Philadelphia: WB Saunders, 1969:14-60.

8 Abbassi V, Aldige C. Evaluation of sodium L-thyroxine (T4) requirement in replacement therapy of hypothyroidism F Pediatr 1977;90:298-301.

9 Tanner JM, Whitehouse RH, Takaishi M. Standards from birth to maturity for height, weight, height velocity and weight velocity: British children, 1965. Part I. Arch Dis Child 1966;41:454-71.

10 Tanner JM, Whitehouse RH, Takaishi M. Standards from birth to maturity for height, weight, height velocity and weight velocity: British children, 1965. Part II. Arch Dis Child 1966;41:613-35.

11 Tanner JM, Whitehouse RH, Cameron N, et al. Assessment of skeletal maturity and prediction of adult height. 2nd Ed. London: Academic Press, 1983.

12 Tanner JM. Growth at adolescence. 2nd Ed. Oxford: Blackwell Scientific Publications, 1978 .

13 Zachmann M, Prader A, Kind HP, Haflinger H, Budliger $\mathrm{H}$. Testicular volume during adolescence. Helv Paediatr Acto 1974;29:61-72.

14 Marshall WA, Tanner JM. Variations in pattern of pubertal changes in boys. Arch Dis Child 1970;45:13-23.

15 Marshall WA, Tanner JM. Variations in pattern of pubertal changes in girls. Arch Dis Child 1969;44:291-303.

16 Pringle PJ, Stanhope R, Hindmarsh P, Brook CGD Abnormal pubertal development in primary hypothyroidism. Clin Endocrinol (Oxf) 1988;28:479-86.

17 Preece MA. Prediction of adult height: methods and problems. Acta Paediatr Scand 1988;347(suppl):4-11.

18 Abbassi V, Rigterink E, Cancellieri RP. Clinical recognition of juvenile hypothyroidism in the early stage. Clin Pediatr (Phila) 1980;19:782-6.

19 Body J-J, Demeester-Mirkine N, Borkowski A, Suciu S, Corvilain J. Calcitonin deficiency in primary hypothyroidism. 7 Clin Endocrinol Metab 1986; 62:700-3.

20 Coindre J-M, David J-P, Reviere L, et al. Bone loss in hypothyroidism with hormone replacement. A histomorphometric study. Arch Intern Med 1986;146:48-53.

21 Stanhope R, Brook CGD. The effect of GnRH analogue on height prognosis in growth hormone deficiency and normal puberty. Eur $\mathcal{F}$ Pediatr 1988;148:200-2. 